\title{
Susceptibility of Candida species isolated from immunocompromised patients to antifungal agents
}

\author{
P. Badiee, ${ }^{7}$ A. Alborzi, ${ }^{7}$ E. Shakiba, ${ }^{7}$ S. Farshad ${ }^{7}$ and A. Japoni ${ }^{7}$
}

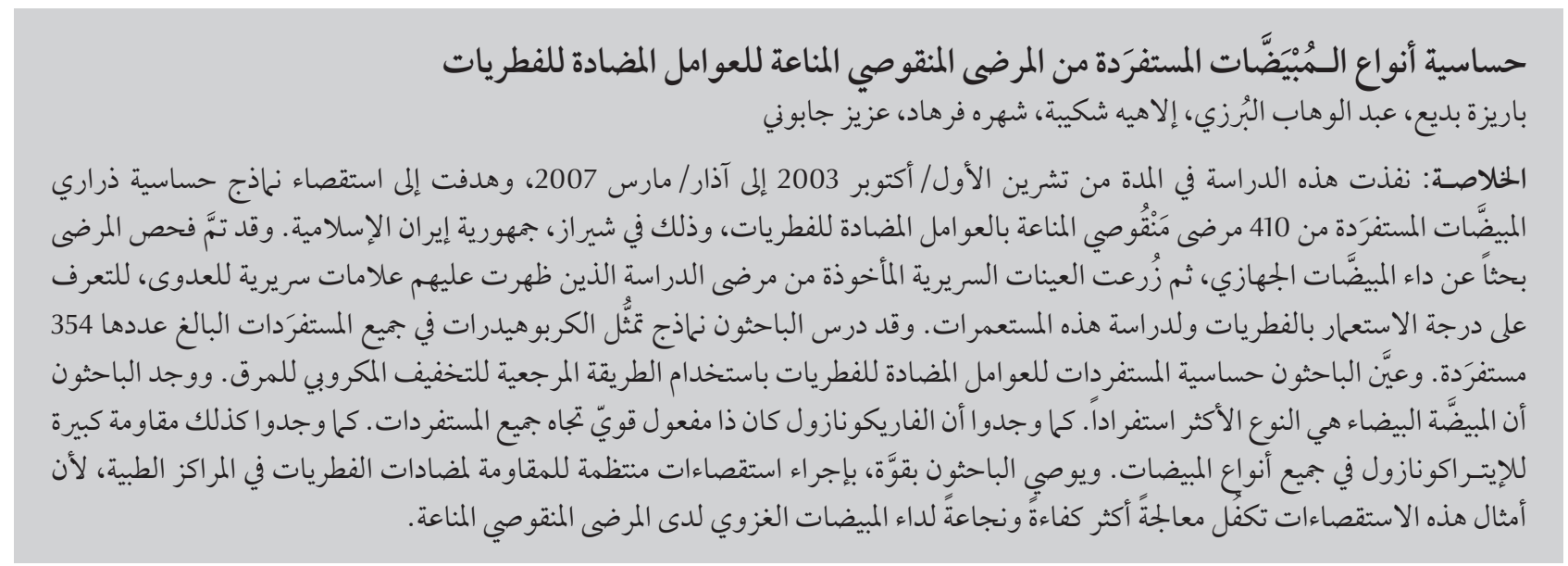

ABSTRACT This study was carried out from October 2003 to March 2007 to investigate susceptibility patterns to antifungals of Candida strains isolated from 410 immunocompromised patients in Shiraz, Islamic Republic of Iran. Patients were checked for systemic candidiasis. Fungal colonization was determined and clinical samples collected from those patients with clinical signs of infections were examined. The carbohydrate assimilation patterns of all 354 isolates were studied. Susceptibility of the isolates to antifungal agents was determined using the reference broth microdilution method. Candida albicans was the species most often isolated. Voriconazole was highly active against all the isolates. Major resistance to itraconazole was observed in all Candida spp. Regular investigations into antifungal resistance in medical centres is highly recommended as this will result in more efficient management of invasive candidiasis in immunocompromised patients.

\section{Sensibilité aux antifongiques des espèces de Candida isolées chez des patients immunodéprimés}

RÉSUMÉ La présente étude, réalisée entre octobre 2003 et mars 2007, a recherché les évolutions de la sensibilité aux antifongiques des souches de Candida isolées chez 410 patients immunodéprimés dans la ville de Chiraz (République islamique d'Iran). Tous les patients ont été examinés à la recherche d'une candidose systémique. Une colonisation fongique a été constatée et les échantillons cliniques prélevés chez les patients présentant des signes d'infection ont été analysés. Le profil d'assimilation des hydrates de carbone de chacun des 354 isolats a été étudié. La sensibilité des isolats aux antifongiques a été déterminée aux moyens de la méthode de référence de microdilution en milieu liquide. Candida albicans s'est révélé être l'espèce la plus souvent isolée. Le voriconazole était hautement actif contre tous les isolats. Une résistance importante de toutes les espèces de Candida à l'itraconazole a été observée. Des analyses régulières de la résistance aux antifongiques dans les centres médicaux sont fortement recommandées, car les résultats permettront une prise en charge plus efficace de la candidose systémique chez les patients immunodéprimés.

'Microbiology Research Centre, Shiraz University of Medical Sciences, Shiraz, Islamic Republic of Iran (Correspondence to P. Badiee: badieep@ sums.ac.ir).

Received: 16/03/09; accepted 08/07/09 


\section{Introduction}

There has been an increase in serious fungal infections in recent years, and there is a need for new antifungal agents. Unlike the development of antibacterial agents, relatively few drug targets in fungi have been used in the development of currently available antifungal agents [1]. Resistance among Candida spp. to antifungal drugs is an increasing problem in immunocompromised patients [2].

Pathogenic fungi represent a serious threat to the lives and health of immunocompromised patients. Until recently, treatment of fungal infections was started with drugs, including azoles and polyenes, which induce severe side-effects in the hosts. Only recently has antifungal drug susceptibility testing become an important issue. There are 2 reasons for testing susceptibility to antifungals: therapeutic failure for amphotericin B has been reported for several Candida spp. and fluconazoleresistant fungi have also been reported. There is the potential for selection of non-albicans Candida spp. of yeasts, which may have implications for treatment since many of the non-C. albicans yeasts, such as C. glabrata and C. krusei, are inherently less susceptible than $C$. albicans to fluconazole [3].

The aim of the present study was to examine geographic trends in the activities of antifungal agents against Candida spp. isolated from immunocompromised patients admitted in a large teaching hospital, and by doing so to promote their effective management. The hospital is the only centre for solid organ transplant and chemotherapy in the south of the Islamic Republic of Iran.

\section{Methods}

From October 2003 to March 2007, 410 immunocompromised patients (from transplant and oncology units) were followed up for invasive fungal infections in Nemazi Hospital, a large teaching hospital in Shiraz University of Medical Sciences, Shiraz, southern Islamic Republic of Iran. We checked for fungal colonization of patients, and in those who had clinical signs of infection, clinical samples (blood, urine, oesophageal, oropharyngeal, vagina, biopsy and broncho-alveolar lavage) were examined for fungal infection using routine methods. The Candida species isolated were stored at $-70^{\circ} \mathrm{C}$ in $10 \%$ glycerol for varying periods of time.

All Candida spp. isolated (354 isolates) were cultured on potato dextrose agar (OXOID Ltd, United Kingdom) twice, for $24 \mathrm{~h}$ and $48 \mathrm{~h}$, at $35^{\circ} \mathrm{C}$ to ensure viability and purity. The carbohydrate assimilation patterns of all the isolates were studied using the API $32 \mathrm{C}$ system, according to the manufacturer's procedure (BioMérieux, France). C. dubliniensis was distinguished from C. albicans by molecular assay [4].

Susceptibility patterns of the isolates to fluconazole, amphotericin B, ketoconazole, nystatin (SIGMA-Aldrichemie GmbH-Steinheim, Germany), itraconazole (Jenssen Pharmaceutical, Belgium), and voriconazole (Pfizer, United Kingdom) were determined by a broth microdilution assay according to the Clinical and Laboratory Standard Institute (CLSI) [5]. Stock solutions of drugs were prepared in dimethyl sulfoxide or water.

Two CLSI quality control strains, $C$. parapsilosis ATCC 22019 and C. krusei ATCC 6258, were tested each time a set of clinical isolates was evaluated [6]. The yeast suspension and antifungal dilution were prepared according to CLSI M27-A2 guidelines [5]. Final concentrations of amphotericin $B$ ranged from 8 to $0.016 \mu \mathrm{g} / \mathrm{mL}$, fluconazole from 128 to $0.250 \mu \mathrm{g} / \mathrm{mL}$, nystatin from 37 to $0.07 \mu \mathrm{g} / \mathrm{mL}$ and itraconazole, ketoconazole and voriconazole from 16 to $0.032 \mu \mathrm{g} / \mathrm{mL}$. In each series, 1 positive control with no drugs and 1 negative control with no fungal suspensions were included. The plates were sealed and incubated at $35^{\circ} \mathrm{C}$. After $24 \mathrm{~h}$ and $48 \mathrm{~h}$ visual minimum inhibitory concentration (MIC) end-points were determined with the aid of a mirror. Visual end-points were determined as described in the CLSI guidelines [5]; these recommended end-points for azoles are the lowest drug concentration with a prominent decrease in turbidity (inhibitory concentration that gives 50\% growth reduction), while for amphotericin B and nystatin, the MIC was the drug concentration showing complete inhibition of growth.

The amount of growth in each tube was compared to that of the growth in a positive control. Antifungal activity was expressed as the MIC of each isolate to the drug. The resistance cut-off points used were according to CLSI guidelines [5] or based on previous investigations [7,8]. MIC50 (the MIC at which 50\% of the isolates are inhibited) and MIC90 (the MIC at which $90 \%$ of the isolates are inhibited) were also calculated. Data were entered into SPSS, version 11.5, and were subsequently analysed using descriptive statistics and cross tabulation.

The ethics committee of the Clinical Microbiology Research Centre at Shiraz University of Medical Sciences reviewed and approved the study regarding the patients, who gave written informed consent before participating in the study.

\section{Results}

Of the 354 Candida species isolated, the most abundant were $C$. albicans (48.6\%) followed by C. krusei (17.5\%), C. glabrata (11.3\%), C. kefyr (11.3\%), C. parapsilosis (5.1\%), C. tropicalis (1.7\%) and $C$.dubliniensis (1.7\%) and other Candida species (2.8\%).

There was no significant difference between reading plates at $24 \mathrm{~h}$ and $48 \mathrm{~h}$ of incubation ( $24 \mathrm{~h}$ and $48 \mathrm{~h}$ MICs limits range for isolates were up to $94 \%$ 


\begin{tabular}{|c|c|c|c|c|c|c|c|c|c|c|c|c|c|}
\hline \multirow[t]{2}{*}{ Species } & \multirow{2}{*}{$\begin{array}{l}\text { Total } \\
\text { No. }\end{array}$} & \multicolumn{2}{|c|}{ AMB } & \multicolumn{2}{|c|}{ FLU } & \multicolumn{2}{|c|}{ ITRA } & \multicolumn{2}{|c|}{ KETO } & \multicolumn{2}{|c|}{ VORI } & \multicolumn{2}{|c|}{ NYS } \\
\hline & & No & $\%$ & No. & $\%$ & No. & $\%$ & No. & $\%$ & No. & $\%$ & No. & $\%$ \\
\hline C. albicans & 172 & 12 & 7.0 & 16 & 9.3 & 26 & 15.1 & 10 & 5.8 & 4 & 2.3 & 2 & 1.2 \\
\hline C. krusei & 62 & 6 & 10.0 & 59 & 95.2 & 53 & 85.5 & 1 & 1.6 & 2 & 3.2 & 1 & 1.6 \\
\hline C. glabrata & 40 & 6 & 15.0 & 38 & 95.0 & 34 & 85.0 & 0 & - & 0 & - & 0 & - \\
\hline C. kefyr & 40 & 4 & 10.0 & 2 & 5.0 & 11 & 27.5 & 0 & - & 0 & - & 0 & - \\
\hline C. parapsilosis & 18 & 4 & 22.3 & 5 & 27.7 & 10 & 55.5 & 0 & - & 0 & - & 2 & 11.1 \\
\hline Other ${ }^{\mathrm{a}}$ & 10 & 0 & - & 4 & 40.0 & 2 & 20.0 & 0 & - & 0 & - & 0 & - \\
\hline C. tropicalis & 6 & 2 & 33.3 & 2 & 33.3 & 0 & - & 0 & - & 0 & - & 0 & - \\
\hline C. dubliniensis & 6 & 0 & - & 0 & - & 0 & - & 0 & - & 0 & - & 0 & - \\
\hline Total & 354 & 34 & 9.6 & 126 & 35.5 & 136 & 38.4 & 11 & 3.1 & 6 & 1.7 & 5 & 1.4 \\
\hline
\end{tabular}

${ }^{a} 2$ cases each of C. famata, C. lusitanae, C. zeylanides and 4 cases of C. apicolata.

Resistance was defined as: amphotericin $B(A M B)>1 \mu \mathrm{g} / \mathrm{mL}$; fluconazole $(F L U) \geq 64 \mu \mathrm{g} / \mathrm{mL}$; itraconazole (ITRA) $\geq 1 \mu \mathrm{g} / \mathrm{mL} ; \mathrm{ketoconazole}(\mathrm{KETO}) \geq 4 \mu \mathrm{g} / \mathrm{mL}$; voriconazole (VORI) $\geq 8 \mu \mathrm{g} / \mathrm{mL}$; nystatin (NYS) $\geq 16 \mu \mathrm{g} / \mathrm{mL}[5,7,8]$.

the same); we therefore report findings on plates incubated for $48 \mathrm{~h}$. Table 1 summarizes the resistance to antifungal agents: overall, nystatin was the most effective against all Candida species (lowest resistance) but use of this agent is limited to mucosal infections.

Voriconazole was also highly active against all the isolates (Table 2). All Candida species except $2.3 \%$ of C. albicans and $3.2 \%$ of C. krusei were susceptible to voriconazole. C. parapsilosis was the most sensitive species to voriconazole (MIC90: $0.032 \mu \mathrm{g} / \mathrm{mL}$ and MIC50: $0.032 \mu \mathrm{g} / \mathrm{mL}$ ) and C. krusei the least sensitive (MIC90: $2 \mu \mathrm{g} / \mathrm{mL}$ and MIC50: $0.250 \mu \mathrm{g} / \mathrm{mL})$. Susceptibilities for all isolates are given in Table 2.

Among the 354 isolates studied, a total of 9 strains (3 C. albicans, 2 C. glabrata, 1 C. kefyr, and 3 C. krusei) were resistant to both itraconazole and amphotericin B. Six strains (4 C. albicans, 1 C. glabrata, 1 C. krusei) were resistant to fluconazole and itraconazole, 4 strains (3 C. albicans, 1 C. krusei) to itraconazole and ketoconazole, and 6 strains $(2 \mathrm{C}$. albicans, 4 C. krusei) to itraconazole and voriconazole. One C. albicans isolate from the abdominal fluid of a male who had had a liver transplant was resistant to amphotericin B, fluconazole, ketoconazole, and itraconazole. He died 2 months after transplantation. In 26 strains highly resistant to fluconazole
$[\mathrm{MIC} \geq 64 \mu \mathrm{g} / \mathrm{mL}]$, voriconazole MICs were $1-4 \mu \mathrm{g} / \mathrm{mL}$. In 15 strains highly resistant to itraconazole [MIC $\geq 1 \mu \mathrm{g} / \mathrm{mL}$, voriconazole MICs were also consistently higher, ranging from 1 $\mu \mathrm{g} / \mathrm{mL}$ to $16 \mu \mathrm{g} / \mathrm{mL}$.

\section{Discussion}

Nearly half the cases of haematogeneous candidiasis are now reported to be attributed to Candida spp. other than C. albicans [9]. In Switzerland the distribution of Candida spp. remained stable between 1991 and 2000, with C. albicans, C. glabrata and C. krusei accounting for $66 \%, 14 \%$ and $2 \%$ of all cases of candidaemia respectively [10]. These data indicate that non-albicans Candida spp. and their susceptibility patterns must be considered when treating immunocompromised patients.

We found that voriconazole was more active than fluconazole and itraconazole against all the Candida isolates tested. These results lend support to findings reported previously [11]. Fluconazole has a broad therapeutic range with low toxicity. Prolonged or repeated exposure to low-dose fluconazole was associated with increased frequency of fluconazole resistance in C. albicans isolates [12]. In our study, $64.5 \%$ of total Candida species were sensitive to fluconazole, and dose-dependent susceptibility was seen in 9 isolates.

Long-term itraconazole prophylaxis is associated with reduction in susceptibility. Resistance to fluconazole and itraconazole were mostly noted in C. krusei and C. glabrata isolates; in one study $72 \%$ of C. glabrata isolates from patients with advanced cancer were resistant to both fluconazole and itraconazole [13]. In our study, major resistance to itraconazole was observed in $85.5 \%$ of isolates of C. krusei and $85.0 \%$ of C. glabrata, and 102 strains showed dose-dependent susceptibility to itraconazole MICs of 0.25 and 0.5 $\mu \mathrm{g} / \mathrm{mL}$. Swinn et al. reported 55\% and $65 \%$ of the non-albicans yeast isolates were susceptible to itraconazole and fluconazole respectively [14].

We found species were either resist to 2 antifungal agents or had high MIC for some antifungal agents. Consistent with some previous reports, isolates with elevated MICs for 1 azole were generally less susceptible to all the azoles. Crosstabulation of voriconazole, fluconazole, and itraconazole MICs indicated that voriconazole MICs rose with fluconazole and itraconazole MICs $[14,15]$.

In recent years, $C$. glabrata has become a significant cause of fungal infections [16]. This yeast has low intrinsic susceptibility to azole derivatives and it is able to acquire resistance during 


\begin{tabular}{|c|c|c|c|}
\hline \multirow[t]{2}{*}{ Organism ${ }^{\mathrm{a}} /$ antifungal agent } & \multicolumn{3}{|c|}{ Minimum inhibitory concentration (mg/mL) } \\
\hline & Range & $50 \%$ & $90 \%$ \\
\hline \multicolumn{4}{|l|}{ C. albicans (172) } \\
\hline Amphotericin B & $0.032-8.0$ & 0.064 & 1.000 \\
\hline Fluconazole & $0.250-32.0$ & 0.250 & 4.000 \\
\hline Itraconazole & $0.032-16.0$ & 0.250 & 0.500 \\
\hline Voriconazole & $0.032-16.0$ & 0.032 & 0.250 \\
\hline Ketoconazole & $0.032-8.0$ & 0.032 & 0.032 \\
\hline Nystatin & 0.14-18.5 & 2.300 & 4.600 \\
\hline \multicolumn{4}{|l|}{ C. krusei (62) } \\
\hline Amphotericin B & $0.032-8.0$ & 0.250 & 1.000 \\
\hline Fluconazole & 1.0-64.0 & 64.000 & 64.000 \\
\hline Itraconazole & $0.250-16.0$ & 0.500 & 2.000 \\
\hline Voriconazole & $0.032-32.0$ & 0.250 & 2.000 \\
\hline Ketoconazole & $0.032-8.0$ & 0.250 & 4.000 \\
\hline Nystatin & $0.290-18.5$ & 2.300 & 4.600 \\
\hline \multicolumn{4}{|l|}{ C. glabrata (40) } \\
\hline Amphotericin B & $0.032-8.0$ & 0.250 & 1.000 \\
\hline Fluconazole & $0.125-64.0$ & 32.000 & 64.000 \\
\hline Itraconazole & $0.125-8.0$ & 0.500 & 1.000 \\
\hline Voriconazole & $0.032-2.0$ & 0.125 & 0.250 \\
\hline Ketoconazole & $0.032-4.0$ & 0.125 & 0.500 \\
\hline Nystatin & $0.580-9.25$ & 2.300 & 4.600 \\
\hline \multicolumn{4}{|l|}{ C. kefyr (40) } \\
\hline Amphotericin B & $0.032-8.0$ & 0.500 & 1.000 \\
\hline Fluconazole & $0.125-16.0$ & 0.250 & 8.000 \\
\hline Itraconazole & $0.250-8.0$ & 0.500 & 0.500 \\
\hline Voriconazole & $0.032-1.0$ & 0.032 & 0.064 \\
\hline Ketoconazole & $0.032-1.0$ & 0.032 & 1.000 \\
\hline Nystatin & $0.580-9.25$ & 2.300 & 2.300 \\
\hline \multicolumn{4}{|l|}{ C. tropicalis (6) } \\
\hline Amphotericin B & $0.250-2.0$ & 0.500 & 0.500 \\
\hline Fluconazole & $0.250-0.500$ & 0.500 & 0.500 \\
\hline Itraconazole & $0.250-0.500$ & 0.250 & 0.500 \\
\hline Voriconazole & $0.032-0.250$ & 0.064 & 0.250 \\
\hline Ketoconazole & $0.032-0.250$ & 0.064 & 0.250 \\
\hline Nystatin & 1.15-2.3 & 2.300 & 2.300 \\
\hline \multicolumn{4}{|l|}{ C. parapsilosis (18) } \\
\hline Amphotericin B & $0.032-16.0$ & 0.250 & 0.500 \\
\hline Fluconazole & $0.125-1.00$ & 0.500 & 1.000 \\
\hline Itraconazole & $0.250-4.0$ & 0.500 & 0.500 \\
\hline Voriconazole & $0.032-0.250$ & 0.032 & 0.032 \\
\hline Ketoconazole & $0.032-0.064$ & 0.032 & 0.064 \\
\hline Nystatin & 1.15-18.5 & 2.500 & 9.250 \\
\hline \multicolumn{4}{|l|}{ C. dubliniensis (6) } \\
\hline Amphotericin B & $0.125-0.250$ & 0.125 & 0.250 \\
\hline Fluconazole & $0.0125-0.5$ & 0.125 & 0.500 \\
\hline Itraconazole & $0.250-0.500$ & 0.250 & 0.250 \\
\hline Voriconazole & $0.032-0.250$ & 0.064 & 0.250 \\
\hline Ketoconazole & $0.032-0.064$ & 0.032 & 0.064 \\
\hline Nystatin & $2.3-4.6$ & 2.300 & 4.600 \\
\hline
\end{tabular}

${ }^{a}$ Candida species with less than 6 isolates are not included in the table. 
treatment. Resistance to itraconazole was mostly noted in C. glabrata and C. krusei isolates. In a study by Seifert et al., all C. glabrata were resistant to itraconazole [17]. All the isolates except 5.8\% of C. albicans, and $1.6 \%$ of C. krusei were susceptible to ketoconazole. Because systemic ketoconazole has a greater propensity to inhibit mammalian cytochrome P450, it has fallen out of clinical use. We found no serious problem with regard to the susceptibility patterns of C. tropicalis, C.dubliniensis, and other Candida spp.

Our study covered severely immunocompromised patients, hospitalized mainly in the oncology and transplantation units. The prevalence of invasive fungal infection ranges from 5\% to 50\% in kidney and liver transplants [18]. Candida spp. and Aspergillus spp. are responsible for more than $80 \%$ of all fungal infections in solid organ transplant recipients and febrile neutropenic patients $[18,19]$, in whom these infections are the major causes of morbidity and mortality [20].

It is common practice to administer triazoles as prophylaxis for fungal infections in our hospitals, and this may explain the high rates of resistance of the clinical Candida strains (all species) to itraconazole (38.4\% resistant), fluconazole (35.5\%) and amphotericin B (9.6\%). For many years, amphotericin B deoxycholate has been a standard therapy for invasive fungal infections [21]. Unfortunately, a side-effect of this agent is nephrotoxicity, and it is often poorly tolerated.

As routinely practised, in empiric therapy antibiotics are given most often to patients before the specific microorganism causing an infection is identified. Empiric antibiotics are typically broad-spectrum, that is, they are effective against a wide variety of possible microorganisms. As shown in our study, itraconazole and fluconazole, with resistance rates of $38.4 \%$ and $35.5 \%$, cannot be good choices for empirical therapy in our region, although they are easily available and cost-effective. The increased loads of intrinsically resistant strains to these 2 antifungal agents may account for the high resistance rates. It seems that voriconazole, although very costly in our region, could serve as a more effective agent against systemic candidiasis in immunocompromised patients.

\section{Conclusions}

As demonstrated, itraconazole and fluconazole resistance are growing concerns in our region; thus, performing regular investigations into antifungal resistance in medical centres for more efficient management of invasive candidiasis in immunocompromised patients is highly warranted. In doing so, determining the sensitivity profile of community strains is possible only through periodic surveillance studies. A more cost-effective and efficient therapy also needs to be considered.

\section{Acknowledgements}

We thank H. Khajehei for providing editorial assistance, Dr M. Moein and M. Didari for contributing to culture and drug concentrations synthesis.

This work was supported by Professor Alborzi Clinical Microbiology Research Centre, Shiraz University of Medical Sciences, Shiraz.

\section{References}

1. Anaissie EJ, McGinnis MR, Pfaller MA. Clinical mycology. Philadelphia, Churchill Livingstone, 2003:456.

2. Magaldi $\mathrm{S}$ et al. In vitro susceptibility of 137 Candida spp. isolates from HIV positive patients to several antifungal agents. Mycopathologia, 2000, 149:63-68.

3. Sobel et al. The evolution of Candida species and fluconazole susceptibility among oral and vaginal isolates recovered from human immunodeficiency virus (HIV)-sero positive and at-risk HIV-sero negative women. Journal of Infectious Diseases, 2001, 183:286-293.

4. Mannarelli BM, Kurtzman CP. Rapid identification of Candida albicans and other human pathogenic yeast by using short oligonucleotides in a PCR. Journal of Clinical Microbiology, 1998, 36:1634-1641.

5. National Committee for Clinical Laboratory Standards. Reference method for broth dilution antifungal susceptibility testing of yeasts. Approved standard, 2nd ed. Wayne, Pennsylvania, National Committee for Clinical Laboratory Standards, 2002 (NCCLS Document M27-A2).

6. Pfaller MA, Yu WL. Antifungal susceptibility testing: new technology and clinical application. Infectious Disease Clinics of North America, 2001, 15:1227-1261.

7. Blignaut $\mathrm{E}$ et al. Antifungal susceptibility of South African oral yeast isolates from HIV/AIDS patients and healthy indi- viduals. Diagnostic Microbiology and Infectious Disease, 2002, 44:169-174.

8. Kronvall G, Karlsson I. Fluconazole and voriconazole multidisk testing of Candida species for disk test calibration and MIC estimation. Journal of Clinical Microbiology, 2001, 39:1422-1428.

9. Singh N. Changing spectrum of invasive candidiasis and its therapeutic implications. European Journal of Clinical Microbiology \& Infectious Diseases, 2001, 7:1-7.

10. Marchetti $O$ et al. Epidemiology of candidemia in Swiss tertiary care hospitals: secular trends, 1991-2000. Clinical Infectious Diseases, 2004, 38:311-320.

11. Sheehan DJ, Tchcock HCA, Sbley CCM. Current and emerging azole antifungal agents. Clinical Microbiology Reviews, 1999, 12:40-79.

12. Lopez J et al. Decrease in Candida albicans strains with reduced susceptibility to fluconazole following changes in prescribing policies. Journal of Hospital Infection, 2001, 48:122-128.

13. Bagg J et al. High prevalence of non-albicans yeasts and detection of anti-fungal resistance in oral flora of patients with advanced cancer. Palliative Medicine, 2003, 17:477-481.

14. Swinne D et al. In vitro activities of voroconazole, fluconazole, itraconazole and amphotericin B against 132 non-albicans bloodstream yeast isolates. Mycoses, 2004, 47:177-183. 
15. Sabatelli F et al. In vitro activities of posaconazole, fluconazole, itraconazole, voriconazole, and amphotericin B against a large collection of clinically important molds and yeasts. Antimicrobial Agents and Chemotherapy, 2006, 50:2009-2015.

16. Spencer $W$ et al. Multiple patterns of resistance to fluconazole in Candida glabrata isolates from a patient with oropharyngeal candidiasis receiving head and neck radiation. Journal of Clinical Microbiology, 2003, 37(12):619-622.

17. Seifert $\mathrm{H}$ et al. In vitro activities of isavuconazole and other antifungal agents against Candida bloodstream isolates. Antimicrobial Agents and Chemotherapy, 2007, 51:1818-1821.
18. Dictar MO et al. Mycoses in the transplanted patient. Medical Mycology, 2000. 38:251-258.

19. Lee GR, Foerster J, Lukens J. Wintrobe's clinical hematology, 10th ed. Baltimore, Williams \& Wilkins, 1999:1862-1888.

20. Patterson TF. New agents for treatment of invasive aspergillosis. Clinical Infectious Diseases, 2002, 35:367-369.

21. Flückiger $U$ et al. Treatment options of invasive fungal infections in adults. Swiss Medical Weekly, 2006, 136(29-3):447-463.

\section{Combat drug resistance: No action today, no cure tomorrow}

Antimicrobial resistance is not a new problem but one that is becoming more dangerous. Many countries are taking action, but urgent and consolidated efforts are needed to avoid regressing to the pre-antibiotic era.

On World Health Day 2011 on 7 April, the World Health Organization (WHO) issued a call for action to halt the spread of antimicrobial resistance by introducing a six-point policy package for all countries to combat antimicrobial resistance.

WHO is calling on everyone to think, act and take responsibility for combating drug resistance including: policymakers and planners, the public and patients, practitioners and prescribers, pharmacists and dispensers, the pharmaceutical industry.

Although governments need to take the lead and develop national policies to combat drug resistance, health professionals, civil society and other groups can also make important contributions. For example, doctors and pharmacists can prescribe and dispense only the drugs that are required to treat a patient, rather than automatically giving either the newest or best-known medicines. Patients can stop demanding that doctors give them antibiotics when they may not be appropriate. Health professionals can help rapidly reduce the spread of infection in health care facilities.

Further information about WHO's six-point policy package to combat drug resistance can be found at: http://www. who.int/world-health-day/2011/en/index.html 